\title{
Effect of Boundary-Layer Bleed Hole Inclination Angle and Scaling on Flow Coefficient Behavior
}

Michael B. Eichorn and Paul J. Barnhart

Case Western Reserve University, Cleveland, Ohio

David O. Davis, Manan A. Vyas, and John W. Slater

Glenn Research Center, Cleveland, Ohio 


\section{NASA STI Program . . . in Profile}

Since its founding, NASA has been dedicated to the advancement of aeronautics and space science. The NASA Scientific and Technical Information (STI) program plays a key part in helping NASA maintain this important role.

The NASA STI Program operates under the auspices of the Agency Chief Information Officer. It collects, organizes, provides for archiving, and disseminates NASA's STI. The NASA STI program provides access to the NASA Aeronautics and Space Database and its public interface, the NASA Technical Reports Server, thus providing one of the largest collections of aeronautical and space science STI in the world. Results are published in both non-NASA channels and by NASA in the NASA STI Report Series, which includes the following report types:

- TECHNICAL PUBLICATION. Reports of completed research or a major significant phase of research that present the results of NASA programs and include extensive data or theoretical analysis. Includes compilations of significant scientific and technical data and information deemed to be of continuing reference value. NASA counterpart of peer-reviewed formal professional papers but has less stringent limitations on manuscript length and extent of graphic presentations.

- TECHNICAL MEMORANDUM. Scientific and technical findings that are preliminary or of specialized interest, e.g., quick release reports, working papers, and bibliographies that contain minimal annotation. Does not contain extensive analysis.

- CONTRACTOR REPORT. Scientific and technical findings by NASA-sponsored contractors and grantees.
- CONFERENCE PUBLICATION. Collected papers from scientific and technical conferences, symposia, seminars, or other meetings sponsored or cosponsored by NASA.

- SPECIAL PUBLICATION. Scientific, technical, or historical information from NASA programs, projects, and missions, often concerned with subjects having substantial public interest.

- TECHNICAL TRANSLATION. Englishlanguage translations of foreign scientific and technical material pertinent to NASA's mission.

Specialized services also include creating custom thesauri, building customized databases, organizing and publishing research results.

For more information about the NASA STI program, see the following:

- Access the NASA STI program home page at http://www.sti.nasa.gov

- E-mail your question to help@sti.nasa.gov

- Fax your question to the NASA STI Information Desk at 443-757-5803

- Phone the NASA STI Information Desk at 443-757-5802

- Write to: STI Information Desk NASA Center for AeroSpace Information 7115 Standard Drive Hanover, MD 21076-1320 
NASA/TM-2013-217843

AIAA-2013-0424

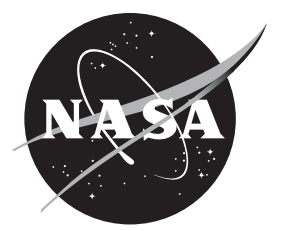

\section{Effect of Boundary-Layer Bleed Hole Inclination Angle and Scaling on Flow Coefficient Behavior}

Michael B. Eichorn and Paul J. Barnhart

Case Western Reserve University, Cleveland, Ohio

David O. Davis, Manan A. Vyas, and John W. Slater

Glenn Research Center, Cleveland, Ohio

Prepared for the

51st Aerospace Science Conference

sponsored by the American Institute of Aeronautics and Astronautics

Grapevine, Texas, January 7-10, 2013

National Aeronautics and

Space Administration

Glenn Research Center

Cleveland, Ohio 44135 


\section{Acknowledgments}

The authors would like to thank R.C. Clark, B.T. Seifert, R.G. Senyitko, J.M. Lucero, D.W. Hammett, and S.M. Velez of NASA Glenn Research Center for matters concerning the wind tunnel and gas bench operation. M.B. Eichorn thanks S.M. Hirt of NASA Glenn Research Center for advice and guidance in experimental design and data analysis. Funding from the Aerospace Sciences Project of the NASA Fundamental Aeronautics Program is gratefully acknowledged.

This report contains preliminary findings, subject to revision as analysis proceeds.

This work was sponsored by the Fundamental Aeronautics Program at the NASA Glenn Research Center.

Level of Review: This material has been technically reviewed by technical management.

Available from

NASA Center for Aerospace Information 7115 Standard Drive

Hanover, MD 21076-1320
National Technical Information Service 5301 Shawnee Road Alexandria, VA 22312 


\title{
Effect of Boundary-Layer Bleed Hole Inclination Angle and Scaling on Flow Coefficient Behavior
}

\author{
Michael B. Eichorn and Paul J. Barnhart \\ Case Western Reserve University \\ Cleveland, Ohio 44106 \\ David O. Davis, Manan A. Vyas, and John W. Slater \\ National Aeronautics and Space Administration \\ Glenn Research Center \\ Cleveland, Ohio 44135
}

\begin{abstract}
Phase II data results of the Fundamental Inlet Bleed Experiments study at NASA Glenn Research Center are presented which include flow coefficient behavior for 21 bleed hole configurations. The bleed configurations are all round holes with hole diameters ranging from 0.795 to $6.35 \mathrm{~mm}$, hole inclination angles from $20^{\circ}$ to $90^{\circ}$, and thickness-to-diameter ratios from 0.25 to 2.0. All configurations were tested at a unit Reynolds number of $2.46 \times 10^{7} / \mathrm{m}$ and at discrete local Mach numbers of $1.33,1.62,1.98,2.46$, and 2.92. Interactions between the design parameters of hole diameter, hole inclination angle, and thickness-to-diameter as well as the interactions between the flow parameters of pressure ratio and Mach number upon the flow coefficient are examined, and a preliminary statistical model is proposed. An existing correlation is also examined with respect to this data.
\end{abstract}

\section{Nomenclature}

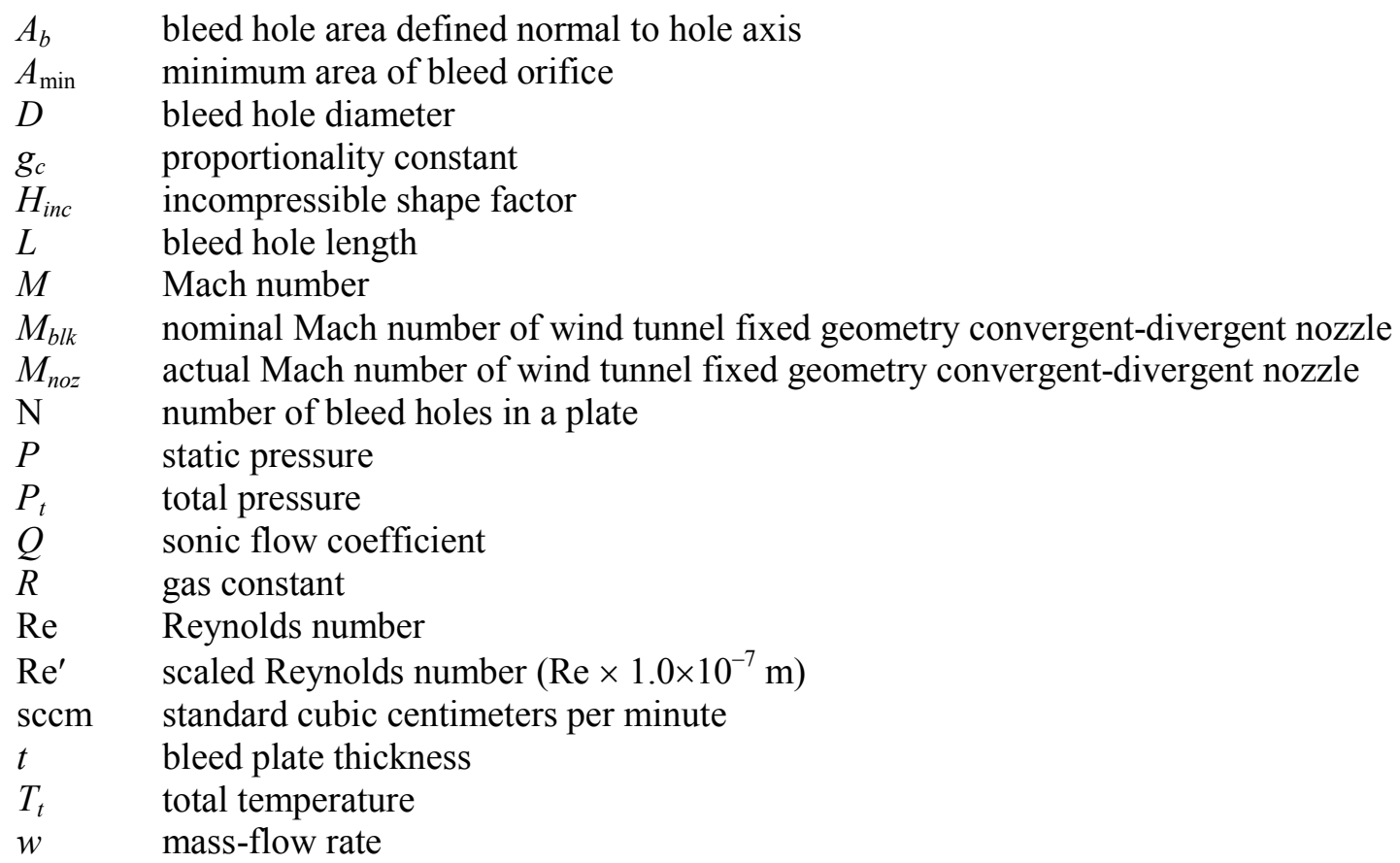

\section{Greek Symbols}

$\alpha \quad$ bleed hole inclination angle

$\delta \quad$ boundary-layer thickness 
$\delta_{1} \quad$ boundary-layer displacement thickness

$\gamma \quad$ ratio of specific heats

\section{Subscripts}

0 pertaining to the wind tunnel plenum chamber condition

air pertaining to air gas

$e \quad$ pertaining to boundary-layer edge condition

$i \quad$ pertaining to ideal conditions

plen pertaining to the bleed plenum condition

wall pertaining to wall condition

\section{Superscripts}

* $\quad$ pertaining to choked conditions

\section{Introduction}

\section{Background}

Boundary-layer control is an important topic in the design of supersonic inlets. In such an inlet, it is important to prevent flow separation and to control the effects of Shock-Wave/Boundary-Layer Interactions (SWBLI). The former can radically change the flow structure, while the latter can displace the shock wave pattern into a less efficient configuration. In addition, the terminal normal shock between the supersonic inlet and the subsonic diffuser is neutrally stable, and to ensure its placement, it is necessary to adjust the mass-flow rate reaching the diffuser in response to perturbations in the engine operation or inlet flow. It is possible to address all of these concerns with mass-flow removal via boundary-layer bleed wherein one or more regions of the inlet wall are porous to remove mass from the boundary layer. Thus, boundary-layer bleed decreases the mass-flow to the engine, mitigates the effects of adverse pressure gradients, and reduces the boundary-layer thickness, and thus, the SWBLI. Bleed configurations often are characterized by the sonic flow coefficient $(Q)$, which is defined as:

$$
Q=\frac{w}{w_{i}^{*}}
$$

where the numerator is the measured mass-flow rate and the denominator is the ideal mass-flow rate under choked conditions:

$$
w_{i}^{*}=\frac{\left(P_{t, e} \cdot A_{b}\right)}{\sqrt{T_{t, e}}} \cdot \sqrt{\frac{\gamma \cdot g_{c}}{R_{\mathrm{air}}}} \cdot\left(\frac{\gamma+1}{2}\right)^{\left(\frac{-(\gamma+1)}{2 \cdot(\gamma-1)}\right)}
$$

The sonic flow coefficient is typically presented as a function of the ratio of bleed plenum pressure to freestream (boundary-layer edge) total pressure $\left(P_{p l e n} / P_{t, e}\right)$. For the present study, the total temperature at the boundary-layer edge $\left(T_{t, e}\right)$ is assumed to be the same as the total temperature in the wind tunnel plenum chamber $\left(T_{t, 0}\right)$.

A large library of flow coefficient data has been developed, beginning with McLafferty (Ref. 1), which was then expanded by Willis (Ref. 2). These collections are very configuration specific as they are multi-hole or slot configurations that only cover a limited range of hole/slot geometries and bleed-hole orientations. Davis (Ref. 3) showed that with two adjacent $90^{\circ}$ holes, the flow coefficient at a choked condition can vary by as much as 6 percent depending on hole orientation. While Slater (Ref. 4) has developed a model for $90^{\circ}$ bleed holes based upon the Willis data, that model should be compared with single hole data where there is no interaction between adjacent holes. 


\section{Fundamental Inlet Bleed Experiments (FIBE)}

The need to develop a more comprehensive experimental database for model development was recognized by NASA Glenn Research Center (GRC) and as a result the Fundamental Inlet Bleed Experiments study (FIBE) was initiated. FIBE aims to create an experimental database to improve modeling of bleed systems through Computational Fluid Dynamics (CFD), as well as to improve supersonic and hypersonic inlets by examining alternate bleed configurations and placement. From 1994 to 1997, GRC conducted bleed research that has been summarized by Davis (Ref. 5). These studies included both single-hole and multi-hole bleed arrays and characterized the flow coefficient behavior as well as the effects of bleed on the boundary layer and on SWBLIs. In 2011 the project was restarted under FIBE with the goal of improving bleed models for CFD codes as well as examining the effects of various configuration parameters.

The FIBE project is being conducted in multiple phases. Phase I testing occurred between April 29, 2011 and September 13, 2011, as reported by Davis (Ref. 6). For Phase I, flow coefficient data were accumulated for a $20^{\circ}$ and a $90^{\circ}$ bleed hole, both having a hole length-to-diameter ratio of 2.0 (see Figure 1), at various Reynolds numbers and Mach numbers. Detailed approach boundary-layer profiles were also obtained. The primary conclusions of the Phase I testing were that the flow coefficient has little dependence on the Reynolds number, at least over the limited range investigated, and that static pressure scaling works reasonably well for the $90^{\circ}$ hole but not for the $20^{\circ}$ hole.

Phase II testing, which began on April 24, and ended on December 11, 2012, examines the effects of the following configuration parameters configuration variables:

- Hole inclination angle $(\alpha)$

- Hole thickness-to-diameter ratio $(t / D)$

- Hole diameter-to-boundary-layer displacement thickness ratio $\left(D / \delta_{1}\right)$

Reported herein are the results of the Phase II study.

\section{FIBE Phase II Test Program}

\section{Test Hardware}

Schematics of "thick" and "thin" bleed plates with reference parameters are shown in Figure 1. As noted in Reference 6, when the cosine of the inclination angle $(\alpha)$ is larger than the plate thickness-todiameter ratio $(t / D)$, the plate is considered "thin" and the minimum flow area exceeds the bleed hole area

normal to the hole axis. For Phase II testing, the single-hole bleed problem was investigated with a Design Of Experiments (DOE) approach. With reference to Figure 1, the critical independent dimensions for the single hole were assumed to be the inclination angle $(\alpha)$, bleed hole diameter $(D)$, and thicknessto-diameter ratio $(t / D)$. While it is natural to consider the length-to-diameter ratio $(L / D)$ rather than the thickness-to-diameter ratio, given that the angles and diameters of interest using length-to-diameter would have resulted in configurations with a very large, and impratical, range of thicknesses. Using these as design parameters for the bleed configurations, the ranges of acceptable values were determined based upon ranges likely to be encountered in engineering use. Applying DOE to these limits and their corresponding midpoints formed a face-centered experimental design with a center-point. Upon arriving at this design, however, the intermediate thickness-to-diameter ratios used in combination with the smallest hole diameter of interest were determined to have a thickness less than would be seen in engineering practice, and as such these configurations were neither constructed nor tested. In all, 21 test articles were fabricated with the specific dimensions given in Table 1. The resulting test configurations yielded four that would be considered to be "thin." Two of these plates (106 and 306) have minimum flow areas approximately 7 percent higher than the bleed hole area and two (109 and 309) had minimum flow areas over twice the bleed hole area. For the smallest hole diameter $(D=0.794 \mathrm{~mm})$, the resulting plate thickness for the two smallest $t / D$ was too thin to pratically fabricate and test so only the thickest 


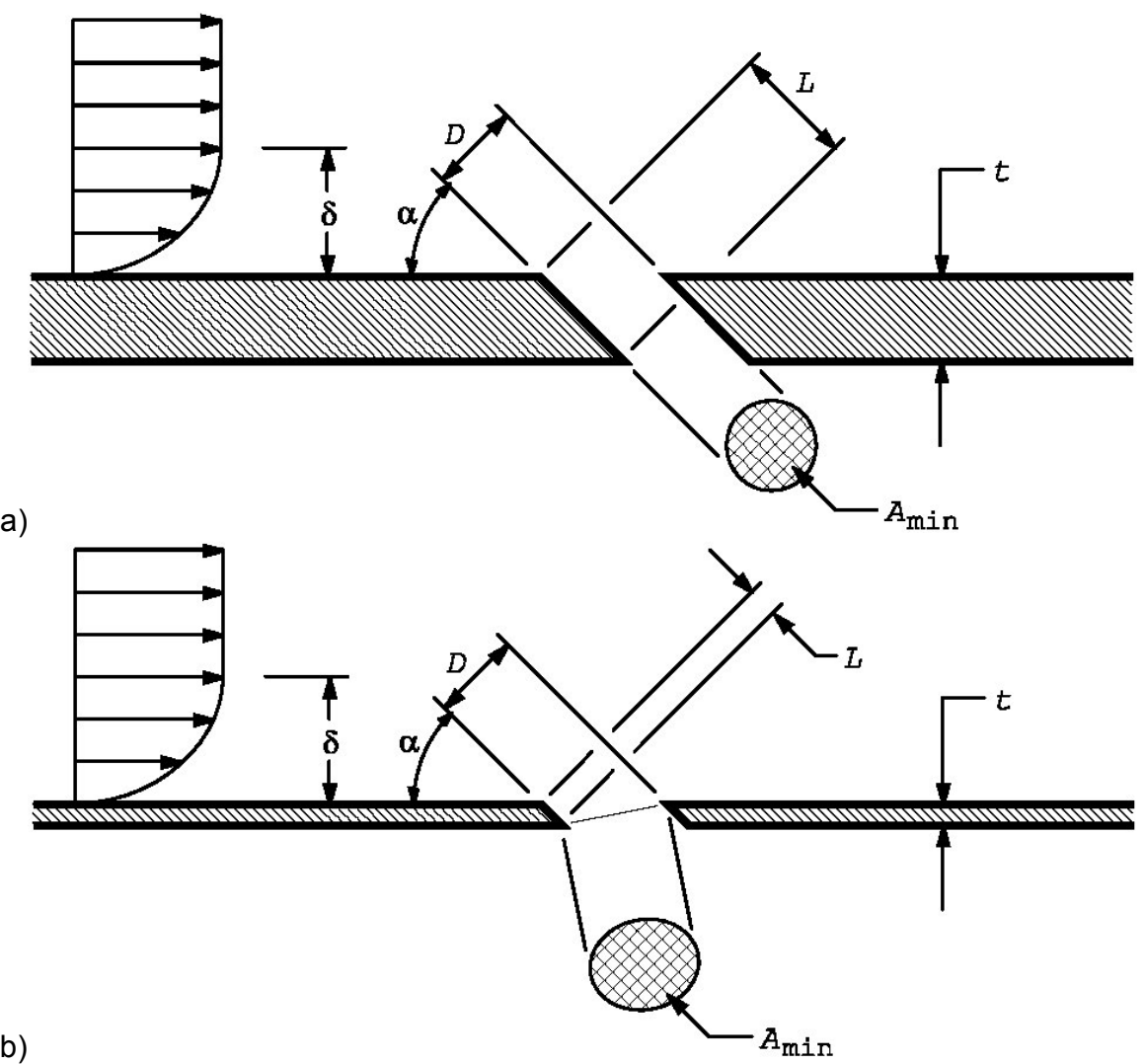

Figure 1.-Schematic of bleed holes. (a) "Thick" bleed plate. (b) "Thin" bleed plate.

TABLE 1.-PHASE II TEST ARTICLE NOMINAL DIMENSIONAL PARAMETERS

\begin{tabular}{|c|c|c|c|c|c|c|c|}
\hline $\begin{array}{c}\text { Config. } \\
\text { No. }\end{array}$ & $\begin{array}{c}\alpha \\
\left({ }^{\circ}\right)\end{array}$ & $\begin{array}{c}D \\
(\mathrm{~mm})\end{array}$ & $\begin{array}{c}t \\
(\mathrm{~mm})\end{array}$ & $t / D$ & $L / D$ & $N$ & $A_{\min } / A_{b}$ \\
\hline 101 & 90 & 6.350 & 12.700 & 2.000 & 2.000 & 1 & 1.0 \\
102 & 90 & 6.350 & 7.144 & 1.125 & 1.125 & 1 & 1.0 \\
103 & 90 & 6.350 & 1.588 & 0.250 & 0.250 & 1 & 1.0 \\
\hline 104 & 55 & 6.350 & 12.700 & 2.000 & 2.442 & 1 & 1.0 \\
105 & 55 & 6.350 & 7.144 & 1.125 & 1.373 & 1 & 1.0 \\
106 & 55 & 6.350 & 1.588 & 0.250 & 0.305 & 1 & $\mathbf{1 . 1}$ \\
\hline 107 & 20 & 6.350 & 12.700 & 2.000 & 5.848 & 1 & 1.0 \\
108 & 20 & 6.350 & 7.144 & 1.125 & 3.289 & 1 & 1.0 \\
109 & 20 & 6.350 & 1.588 & 0.250 & 0.731 & 1 & $\mathbf{2 . 3}$ \\
\hline 301 & 90 & 3.572 & 7.144 & 2.000 & 2.000 & 3 & 1.0 \\
302 & 90 & 3.572 & 4.018 & 1.125 & 1.125 & 3 & 1.0 \\
303 & 90 & 3.572 & 0.893 & 0.250 & 0.250 & 3 & 1.0 \\
\hline 304 & 55 & 3.572 & 7.144 & 2.000 & 2.442 & 3 & 1.0 \\
305 & 55 & 3.572 & 4.018 & 1.125 & 1.373 & 3 & 1.0 \\
306 & 55 & 3.572 & 0.893 & 0.250 & 0.305 & 3 & $\mathbf{1 . 1}$ \\
\hline 307 & 20 & 3.572 & 7.144 & 2.000 & 5.848 & 3 & 1.0 \\
308 & 20 & 3.572 & 4.018 & 1.125 & 3.289 & 3 & 1.0 \\
309 & 20 & 3.572 & 0.893 & 0.250 & 0.731 & 3 & $\mathbf{2 . 3}$ \\
\hline 1501 & 90 & 0.794 & 1.588 & 2.000 & 2.000 & 15 & 1.0 \\
1504 & 55 & 0.794 & 1.588 & 2.000 & 2.442 & 15 & 1.0 \\
1507 & 20 & 0.794 & 1.588 & 2.000 & 5.848 & 15 & 1.0 \\
\hline & & & & & & & \\
\hline
\end{tabular}


value $(t / D=2.0)$ was considered. Sufficient testing time was available such that all of the geometric configurations had at least one flow coefficient curve collected at each tunnel Mach number.

The test articles (bleed plates) used in Phase II differed in configuration from those used in Phase I. The round inserts used in Phase I created a potential problem with the impingement of the jet exiting the bleed hole on the inner surface of the insert when small inclination angles and thick plates were considered. To mitigate this problem, rectangular bleed inserts with longer axial spans were used. Figure 2 shows a comparison of the 108 configuration (see Table 1) incorporated into the Phase I and Phase II bleed inserts.

Like Phase I, the goal of Phase II is to determine the flow coefficient for various configurations of an isolated bleed hole. The objective here is to first understand the behavior of an isolated bleed hole and then later to look at the same hole configuartion as part of an array with various porosities and hole spacings, in order to understand multi-hole interactions. For the present single-hole studies, the hole diameter varies by an order of magnitude which makes flow-rate measurement of a single small hole problematic. CFD performed at GRC, however, suggests that no interaction between holes will occur if the holes are place in a single row spaced at least four diameters apart. Therefore, multiple holes spaced four diameters apart were used for all but the largest diameter as indicated in Table 1. There is a limit, however, to the number of holes that could be placed spanwise on the insert. Ideally, the total bleed hole area would be similar for each configuration and this is indeed true of the single and three-hole configurations. For the smallest hole diameter, only 15 holes could be placed in the plate resulting in a flow area of about $1 / 4$ that of the other configurations. As described below, modifications to the massflow measurement system were made to accurately measure the reduced total flow through the smallest hole configurations. Figure 3 shows representative configurations of the single and multi-hole inserts.

\section{Test Facility}

FIBE Phase I and Phase II testing were conducted in the 15- by $15-\mathrm{cm}$ Supersonic Wind Tunnel (SWT), which is a continuous flow facility with Mach number variation set by interchangeable fixedgeometry convergent-divergent (C-D) nozzle blocks. The current Mach number capability is $M=0.3$ to 0.8

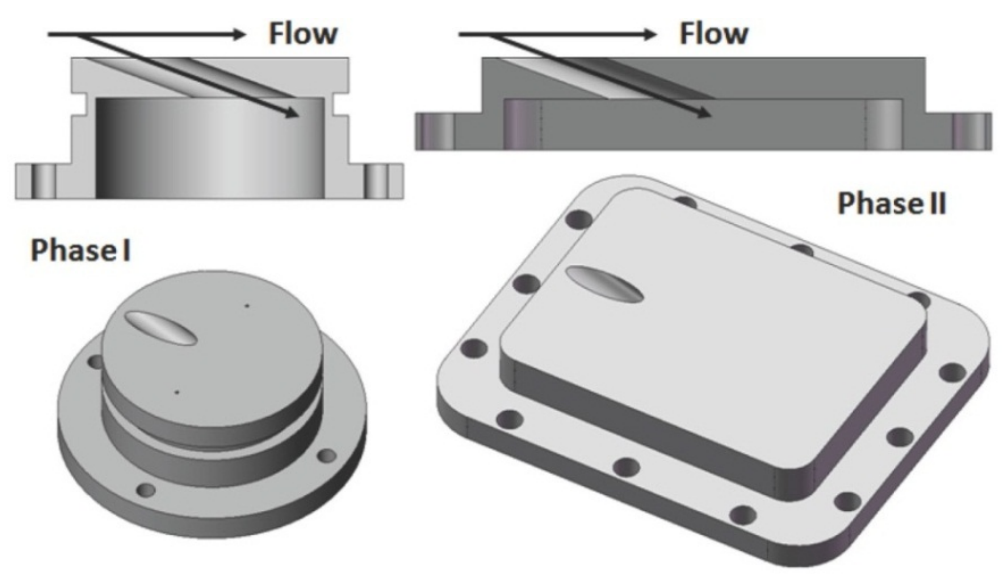

Figure 2.-Comparison of Phase I and Phase II test articles (Configuration 108 shown).

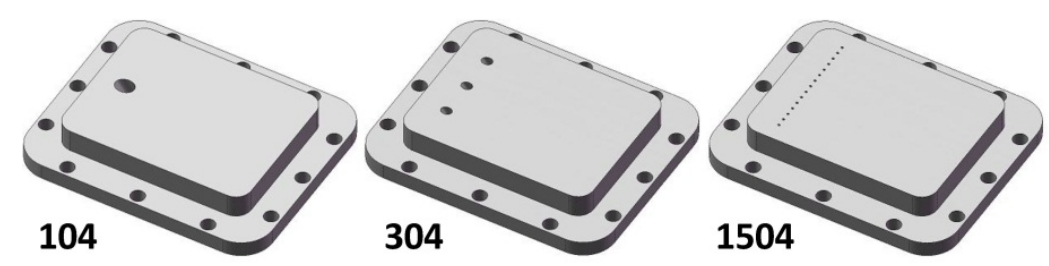

Figure 3.-Phase II single and isolated multi-hole test articles. 


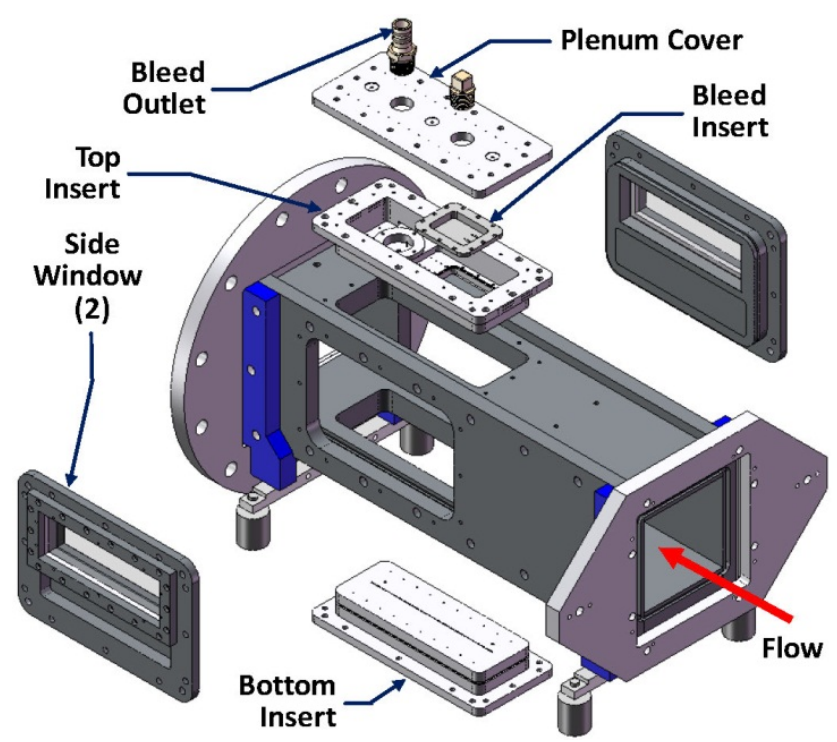

Figure 4.-Bleed setup in 15- by $15-\mathrm{cm}$ SWT test section.

for subsonic operation and $M_{b l k}=1.4,1.7,2.0,2.5$, and 3.0 for supersonic operation. The total temperature is nominally ambient. The wind tunnel is supplied with lab-wide 40 psig combustion air and exhausts to lab-wide Altitude Exhaust which is maintained below $13.8 \mathrm{kPa}(2.0 \mathrm{psia})$. For Phase II, the wind tunnel was configured the same as Phase I except for the aforementioned change to the bleed plate insert.

The 15- by $15-\mathrm{cm}$ SWT test section is configured to accept the test articles as shown in Figure 4 . The top window insert of the test section is machined to accept the test articles shown in Figure 3. A cover plate is attached on the top of the window insert to form the bleed plenum. The bleed flow exhausts from the bleed plenum through a male barb fitting outlet that screws into the plenum cover plate. The side window inserts have schlieren glass installed for flow visualization and the bottom window insert has three rows of axial pressure taps. The location of the Phase II bleed plates relative to the reference boundary-layer profiles is the same as Phase I.

\section{Instrumentation}

The instrumentation used for Phase II is essentially the same as used in Phase I (see Ref. 6). For the present study, the primary measurement of interest is the bleed mass-flow rate. The bleed mass-flow rate is measured by the method of mixtures (Ref. 7), where the mixer gas is methane and its concentration is measured with a Flame Ionization Detector (FID). Details of the bleed mass-flow measurement system and flow equations are given in Reference 6, but the basic operation is to seed the bleed-flow with a trace amount of a hydrocarbon gas, in this case methane, allow the bleed air and methane to thoroughly mix, and then measure the concentration of methane in the mixed bleed-flow. Knowing the methane flow-rate and the mixed-flow methane concentration allows one to calculate the bleed air flow rate. This mass-flow measurement technique is particularly suited to bleed studies since it is scalable to any flow rate simply by changing the range of the hydrocarbon gas flow controller and doesn't rely on a clean uniform flow at the measurement station. Between Phase I and Phase II testing, several improvements to the system were incorporated including:

1. Addition of a second sample pump in series to allow data accumulation at lower bleed plenum pressures.

2. Tweaks to the sample flow-rate regulation system to ensure a more consistent sample flow-rate to FID.

3. Addition of 10 and $1000 \mathrm{sccm}$ methane flow controllers to the existing $100 \mathrm{sccm}$ unit to allow for more accurate measurement over a wider range of bleed flows. 


\section{Operating Conditions}

Data were accumulated at nominal Mach numbers of 1.4, 1.7, 2.0, 2.5, and 3.0. The results of Phase I testing indicated only a weak Reynolds number dependence so the Phase II data were accumulated at only the highest Reynolds number, namely, $2.46 \times 10^{7} / \mathrm{m}\left(7.50 \times 10^{6} / \mathrm{ft}\right)$. Thus, there were a total of five different conditions tested. The five operating conditions are summarized in Table 2. For consistency, the operating condition number assigned is the same as designated in Phase I. Also in Table 2 is the actual Mach number calculated at the nozzle exit plane as well as the local boundary-layer edge Mach number measured at the boundary-layer measurement plane. The distance from the nozzle exit to the boundarylayer measurement plane is $36.36 \mathrm{~cm}$ (14.32 in) so that the edge Mach number is slightly below the nozzle exit Mach number.

TABLE 2.-TEST OPERATING CONDITIONS $\left(\mathrm{Re}^{\prime}=\operatorname{Re} \times 1.0 \times 10^{-7} \mathrm{~m}\right)$
\begin{tabular}{|c|c|c|c|c|c|c|c|}
\hline $\begin{array}{c}\text { Cond. } \\
\text { No. }\end{array}$ & $M_{b l k}$ & $\mathrm{Re}^{\prime}$ & $M_{\text {noz }}$ & $M_{e}$ & $\begin{array}{c}\delta \\
(\mathrm{mm})\end{array}$ & $\begin{array}{c}\delta_{1} \\
(\mathrm{~mm})\end{array}$ & $H_{\text {inc }}$ \\
\hline 003 & 1.4 & 2.46 & 1.389 & 1.333 & 13.2 & 2.37 & 1.323 \\
006 & 1.7 & 2.46 & 1.679 & 1.618 & 12.3 & 2.41 & 1.320 \\
009 & 2.0 & 2.46 & 1.993 & 1.971 & 12.1 & 2.66 & 1.320 \\
012 & 2.5 & 2.46 & 2.506 & 2.463 & 13.1 & 3.44 & 1.311 \\
015 & 3.0 & 2.46 & 3.035 & 2.960 & 12.2 & 3.78 & 1.306 \\
\hline
\end{tabular}

\section{Results and Data Analysis}

\section{Overview}

Sonic flow coefficient curves were collected for each plate at the five operating conditions and over the complete range of the mass-flow measurement apparatus. As such, each data point represents a unique combination of several unique parameters; the sonic flow coefficient $(Q)$, the plenum pressure ratio $\left(P_{p l e n} / P_{t, e}\right)$, the Mach number $(M)$, the bleed hole diameter-to-boundary-layer displacement thickness ratio $\left(D / \delta_{1}\right)$, the thickness-to-diameter ratio $(t / D)$, and the hole inclination angle $(\alpha)$. Given that it is likely that $Q$ is dependent on the other five parameters, the multiple interactions create significant difficulties in data presentation. The thickness-to-diameter ratio, and the hole inclination angle are constant for a given plate, but the plenum pressure ratio and diameter-to-boundary-layer displacement thickness ratio are both dependent on Mach number. In previous work, such as Davis (Ref. 6) and Willis (Ref. 2), it has been shown that flow coefficient curves are largely self-similar for a bleed plate configuration and as such multiple Mach numbers are easily plotted on the same graph.

The most noticeable characteristic as a result of changing a single parameter is that of varying the hole inclination angle. Figure 5 presents the changes observed by maintaining a constant nominal diameter and therefore nominally constant diameter-to-boundary-layer displacement thicknesses for each Mach number. As shown in previous work (Refs. 2 and 6), the change in hole angle (moving down the columns of plots) results in a vastly different apparent shape between a $90^{\circ}$ and a $20^{\circ}$ hole. Interestingly, an examination of the $55^{\circ}$ hole yields a shape similar to that of a $90^{\circ}$ hole while showing a moderate increase in the maximum sonic flow coefficient. Further, the plenum pressure ratio where the flow unchokes is very near that of the $90^{\circ}$ hole. For all bleed configurations, an increase in Mach number resulted in a curve that was scaled down from the previous ones, however for the $20^{\circ}$ holes there is some impact on the rate of change near the point at which the flow becomes un-choked. Figure 5(g) shows that as Mach number increases, the curvature in unchoking the hole transitions from a smooth change in slope to a sharp cusp. Further, like some previous data (Ref. 2), the $20^{\circ}$ case shows a decreasing pressure ratio as the sonic flow coefficient drops. This region of the flow curve beneath the choked value for the $20^{\circ}$ plates exhibited large fluctuations in the plenum pressure ratio; the value shown being a numerical average over a $30 \mathrm{sec}$ time period. 

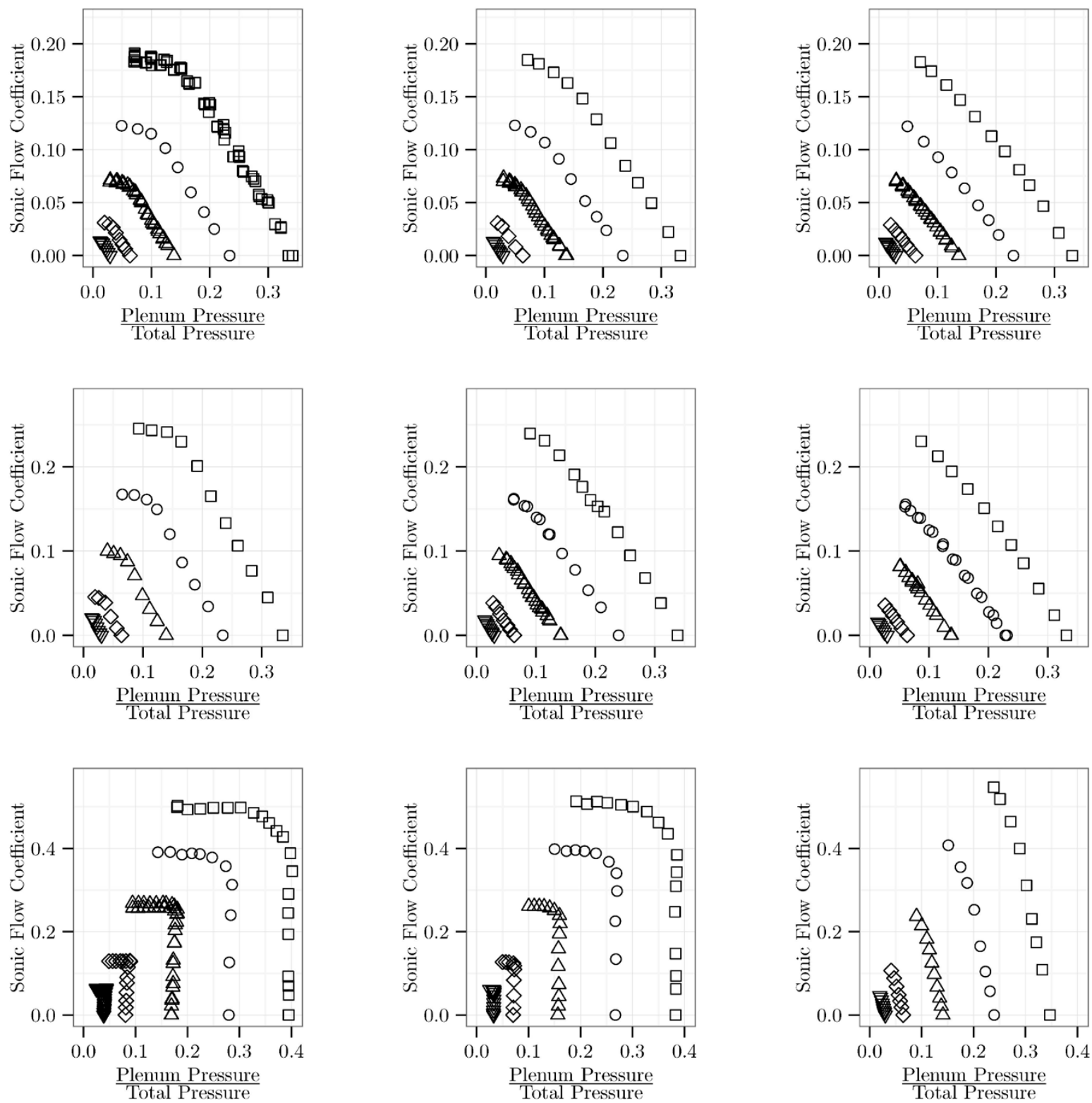

Figure 5.-Flow coefficient curves of selected plates at a constant nominal diameter of $D=6.35 \mathrm{~mm}$. Nominal Mach numbers: $\square-1.4, \bigcirc-1.7, \triangle-2.0, \diamond-2.5, \nabla-3.0$.

The effect of variance in thickness-to-diameter ratio, and thus the length-to-diameter ratio, is also illustrated in Figure 5. Reducing the thickness (moving right across the plot rows) changes the character of the curves. In particular, the critical point where the curve begins to plateau to a choked condition occurs at a lower pressure ratio. For the $20^{\circ}$ hole, the entire curve shifts to a lower pressure ratio. Although the effect of the marginally larger minimum area of plate 106 (Figure 5(f)) cannot be readily discerned, the effect of the significantly larger minimum area of plate 109 is easily discerned whereby the peak value exceeds the thicker plates choked value and shows only a small degree of turning towards a plateau. Unfortunately, the current vacuum pump is not capable of choking all the bleed plate configurations.

Figure 6 examines the effect of changes in hole diameter at the largest thickness-to-diameter ratio. Although the primary interaction variable of interest here is the diameter-to-boundary-layer displacement 
thickness ratio, it should also be noted that the length-to-diameter ratio varies (increases) as the inclination angle is reduced. Starting with the $90^{\circ}$ hole (moving down the left column of plots), there is little change in the flow coefficient between the two larger holes. For the smallest hole, however, there is a significant increase in the flow coefficient which becomes more pronounced as the Mach number is reduced. It is speculated that the reason for this is the smallest hole size draws off flow at a much lower Mach number and thus does not have the shock losses inside the hole that are associated with larger holes. The trend of increasing flow coefficient with decreasing Mach number is consistent with the increasing thickness of the sonic layer as the Mach number is reduced. For the $55^{\circ}$ hole (middle column of plots), the shock losses would be somewhat reduced compared to the $90^{\circ}$ hole and there is observed a consistent trend of slightly increasing flow coefficient with decreasing hole size. For the $20^{\circ}$ hole (right column of plots), the shock losses are minimized and the trend is reversed with the larger holes capturing higher momentum flow that does not experience the shock turning losses of the holes with higher inclination angles.
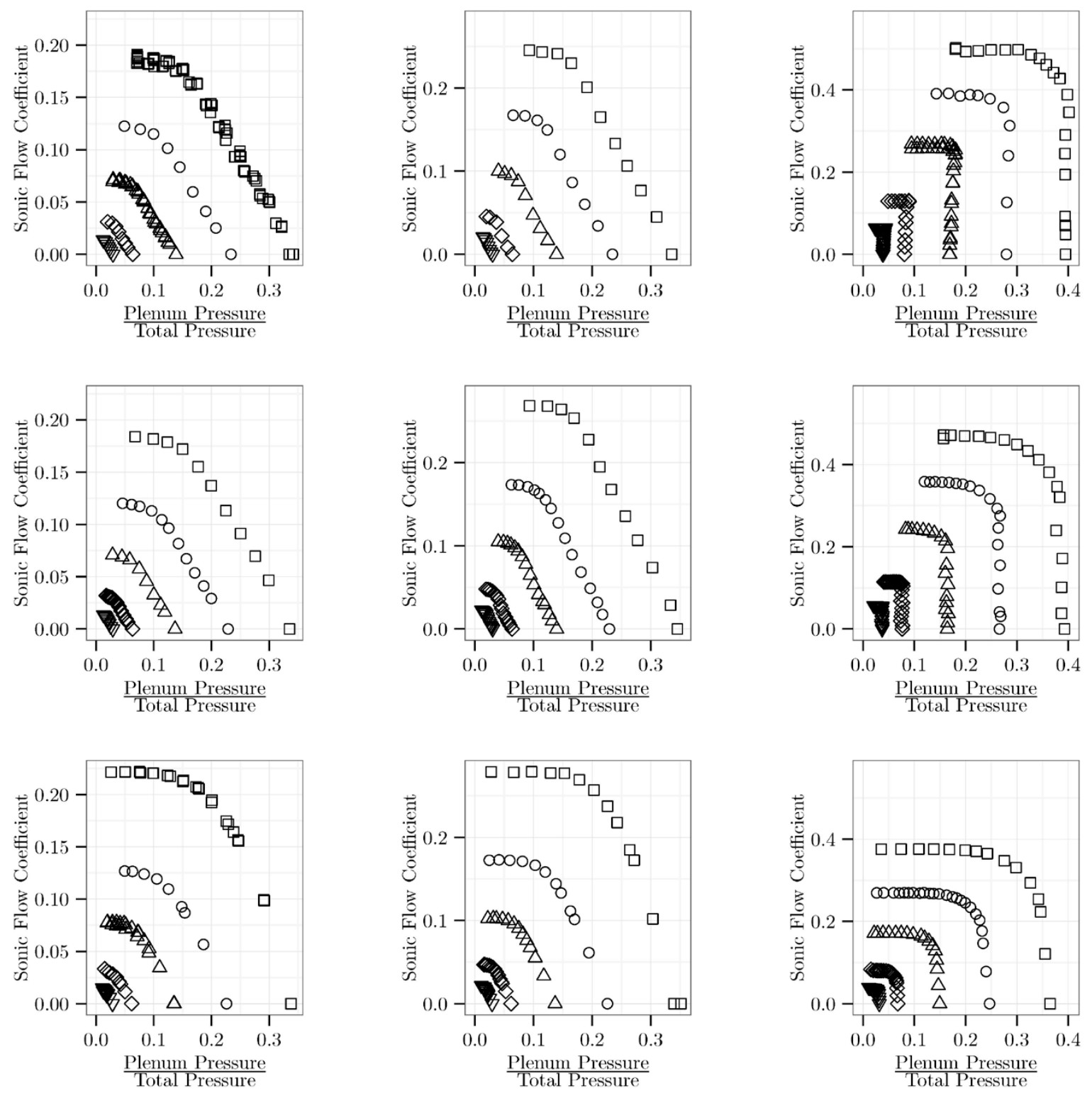

Figure 6.-Flow coefficient curves of selected plates at a constant thickness-to-diameter ratio of 2.0. Nominal Mach numbers: $\square-1.4, \bigcirc-1.7, \triangle-2.0, \diamond-2.5, \nabla-3.0$. 
The similarity of a given configuration across Mach number has led the authors of previous works to consider scaling the sonic flow coefficient and plenum pressure ratio so as to collapse the data to a single distribution. Davis (Ref. 6) concluded that the scaling method presented by Slater (Ref. 4) was a better, but imperfect, fit for single-hole data than the scaling method Davis has previously proposed based upon a semi-empirical correlation of the data collected by Willis. As such, the data can be roughly collapsed by scaling the flow coefficient and plenum pressure ratio to be:

$$
\begin{gathered}
P_{\text {plen }, \text { scaled }}=\frac{\left(P_{\text {plen }} / P_{t, e}\right)}{\left(P_{\text {wall }} / P_{t, e}\right)}=\frac{\left(P_{\text {plen }} / P_{t, e}\right)}{\left(1+\frac{\gamma-1}{2} M_{e}^{2}\right)^{\frac{-\gamma}{\gamma-1}}} \\
Q_{\text {scaled }}=\frac{Q}{\left(P_{\text {wall }} / P_{t, e}\right)}=\frac{Q}{\left(1+\frac{\gamma-1}{2} M_{e}^{2}\right)^{\frac{-\gamma}{\gamma-1}}}
\end{gathered}
$$

The above wall static pressure scaling assumes that the total pressure in the hole is nearly the same as the surface wall static pressure. This is likely a reasonable assumption for holes with large inclination angles as all the freestream total pressure is lost turning the flow through a large angle. As the inclination angle is reduced, however, some of the freestream total pressure is expected to be recovered in the hole and it is thus expected that the above scaling will not work as well, particularly at high flow rates. This suggests that a physics-based model must account for the total pressure recovery in the hole which may be a function of a number of parameters.

Several examples of collapsed data using the equations above for specific bleed holes are given in Figure 7. Unlike the data collected by Davis (Ref. 6), the data from many of these plates collapse very well when this scaling is applied. Of particular note are plates with the smallest nominal thickness-todiameter ratio $(t / D=0.25)$, Figure 7 (a) to (c) (top row of plots), which collapse very well independent of hole angle. That these plates collapse well isn't necessarily surprising inasmuch as very thin plates do not have the same internal shock structure as thicker plates do. Figure 7(d) to (f) (middle row of plots) display the collapse for hole configurations where the nominal thickness-to-diameter ratio is 2.0 and the hole angle is $55^{\circ}$ and in this case the collapse appears to have higher degree of scatter, however there is little apparent trend in Mach number. The final selection, Figure $7(\mathrm{~g})$ to (i), present the $20^{\circ}$ hole data and as Davis (Ref. 6) concluded, the scaling does not work particularly well for $20^{\circ}$ holes. These have a distinct difference in magnitude where the maximum scaled sonic flow coefficient increases with Mach number. Further this tendency is related to the hole diameter as the smaller hole diameters show less separation between the curves.

A comparison of all collapsed data is shown in Figure 8. The values for the $20^{\circ}$ holes are noticeably larger than those of the $90^{\circ}$ and $55^{\circ}$ holes which themselves form two distinct groups. The $90^{\circ}$ holes seem to form tight bands for specific thickness-to-diameter ratios, however both the $55^{\circ}$ and $90^{\circ}$ holes only show a loose grouping where that ratio is small.

\section{Existing Correlation}

As the data were collapsed per the method proposed by Slater (Ref. 4), it is worthwhile to consider that the correlation he proposed was for a bleed configuration that was most similar to the current Plate 102. As shown in Figure 9. The correlation is similar but exact neither in maximum scaled sonic flow coefficient nor in predicting the shape of the curve. As the correlation is based upon the data of Willis (Ref. 2), which is for a multi-hole configuration, some variance is expected as a result of hole-to-hole interactions. 

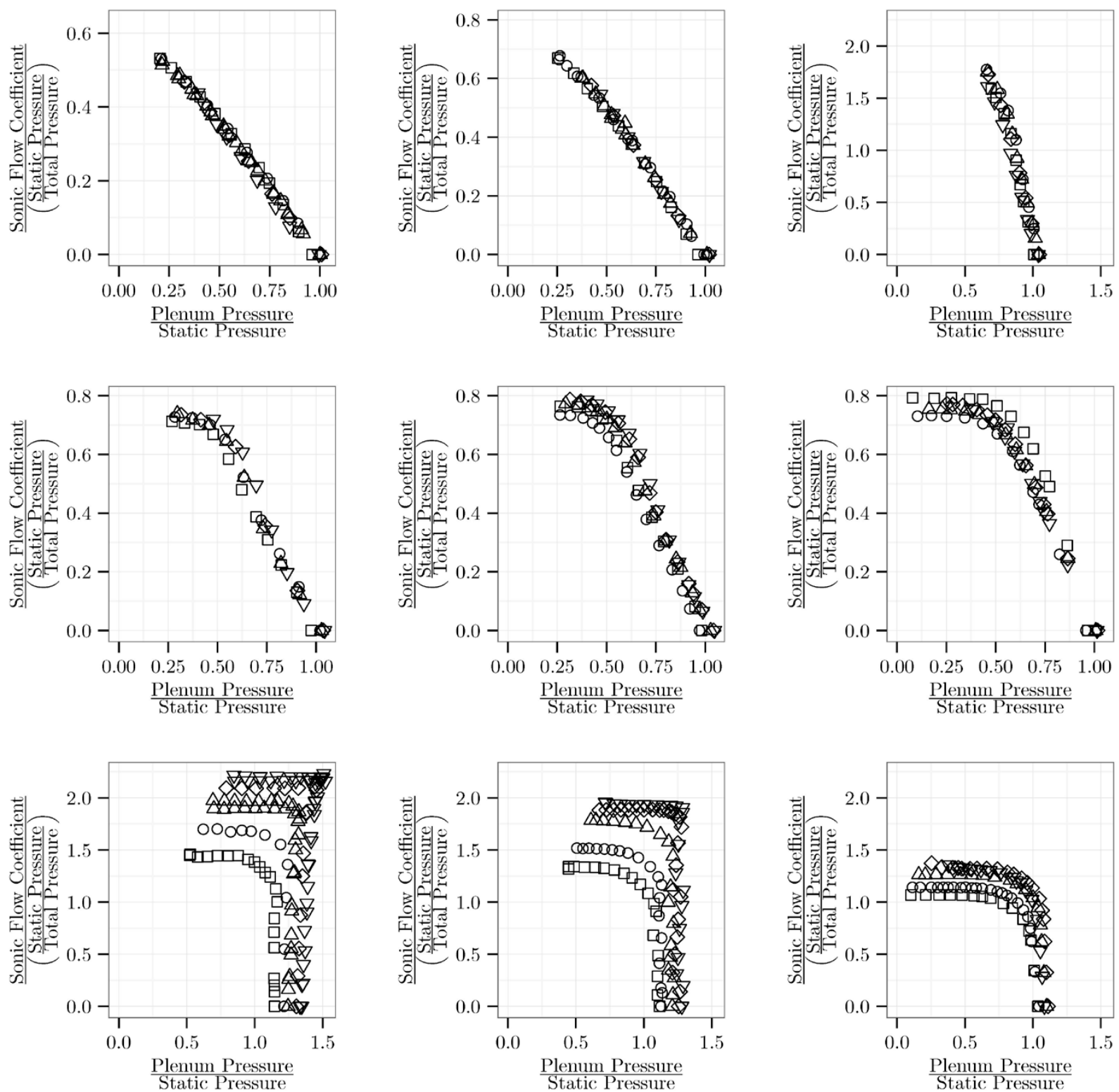

Figure 7.-Flow coefficient curves of selected plates collapsed by pressure ratio. Nominal Mach numbers: $\square-1.4$, $\bigcirc-1.7, \triangle-2.0, \diamond-2.5, \nabla-3.0$.

\section{Statistical Fit}

As the previous correlation is insufficient to describe the breadth of the data collected, a preliminary statistical fit of the data was determined. As the $20^{\circ}$ data included a region of large flow instability and lacks a functional form in pressure ratio at high Mach numbers, the $20^{\circ}$ data was excluded from the model. A theoretical model may be needed to include the $20^{\circ}$ data. The remaining data was considered with the dependent variable as the scaled sonic flow coefficient and the independent variables of scaled plenum pressure ratio, Mach number, hole inclination angle, diameter-to-boundary-layer displacement thickness ratio, and thickness-to-diameter ratio. 

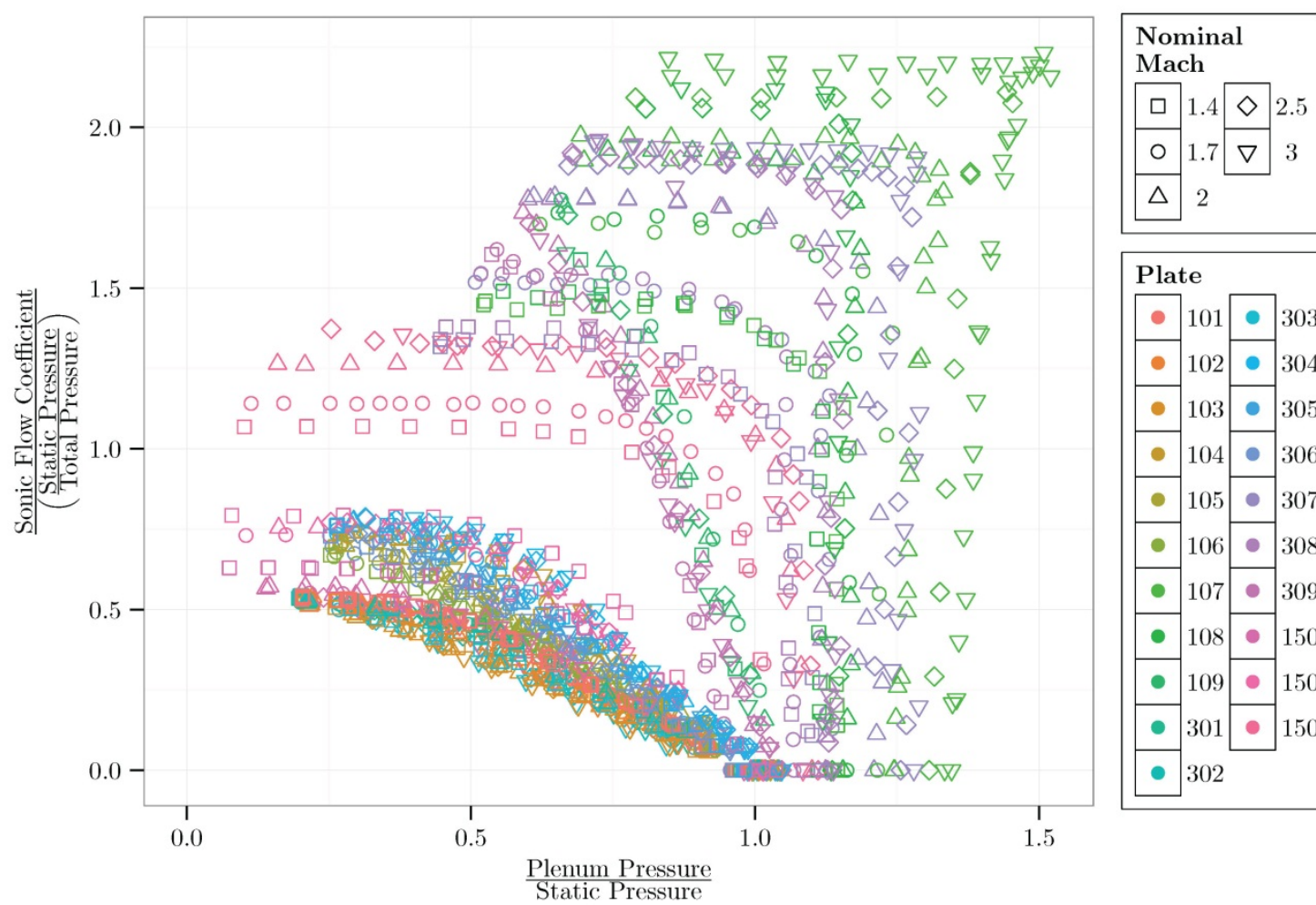

\begin{tabular}{|c|c|c|c|}
\hline \multicolumn{4}{|c|}{ Plate } \\
\hline$\bullet$ & 101 & $\bullet$ & 303 \\
\hline$\bullet$ & 102 & $\bullet$ & 304 \\
\hline$\bullet$ & 103 & $\bullet$ & 305 \\
\hline$\bullet$ & 104 & $\bullet$ & 306 \\
\hline - & 105 & $\bullet$ & 307 \\
\hline$\bullet$ & 106 & $\bullet$ & 308 \\
\hline$\bullet$ & 107 & $\bullet$ & 309 \\
\hline$\bullet$ & 108 & $\bullet$ & 1501 \\
\hline • & 109 & $\bullet$ & 1504 \\
\hline$\bullet$ & 301 & $\bullet$ & 1507 \\
\hline$\bullet$ & 302 & & \\
\hline
\end{tabular}
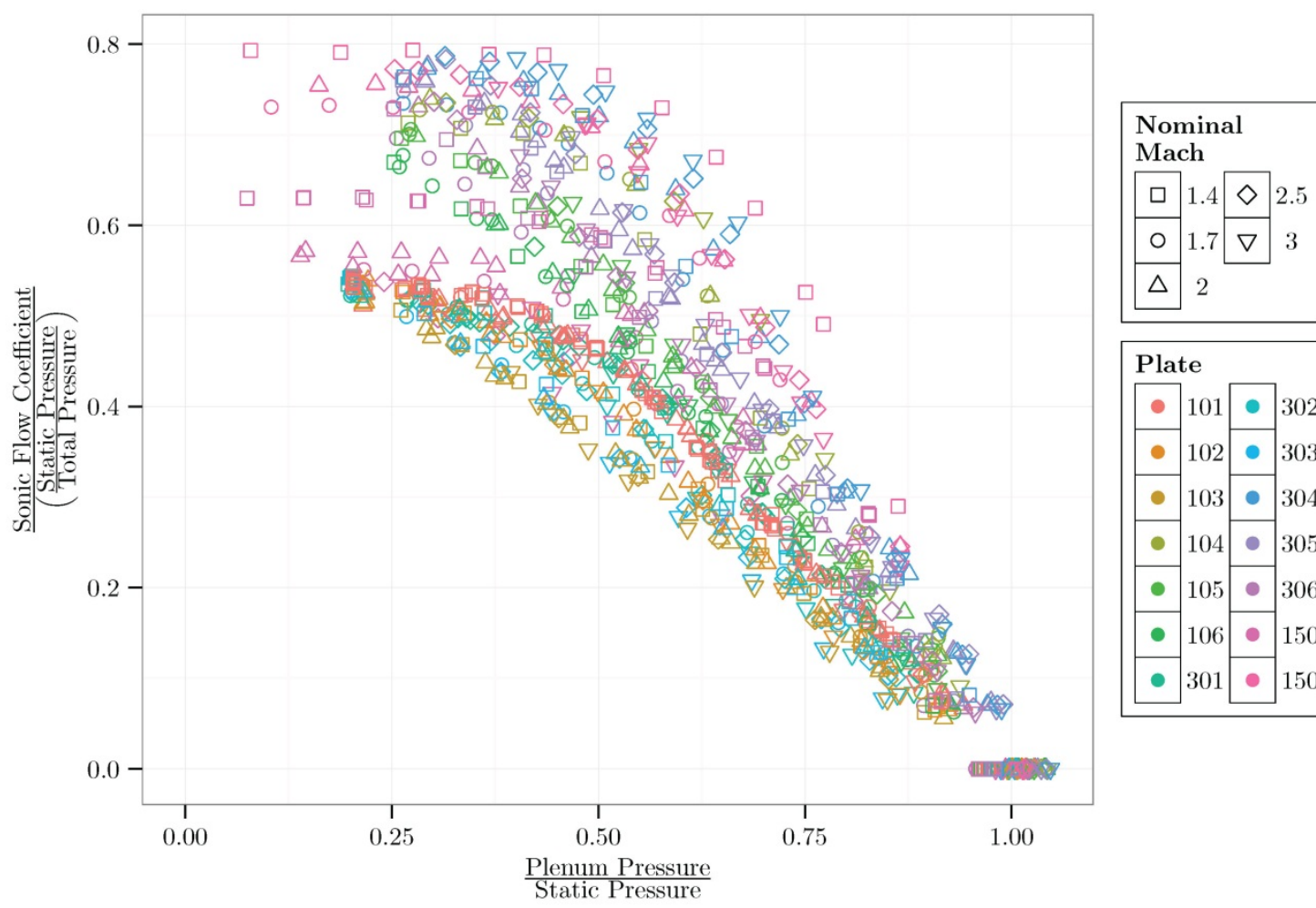

Figure 8.-Collapsed flow coefficient curves for all flow conditions. 


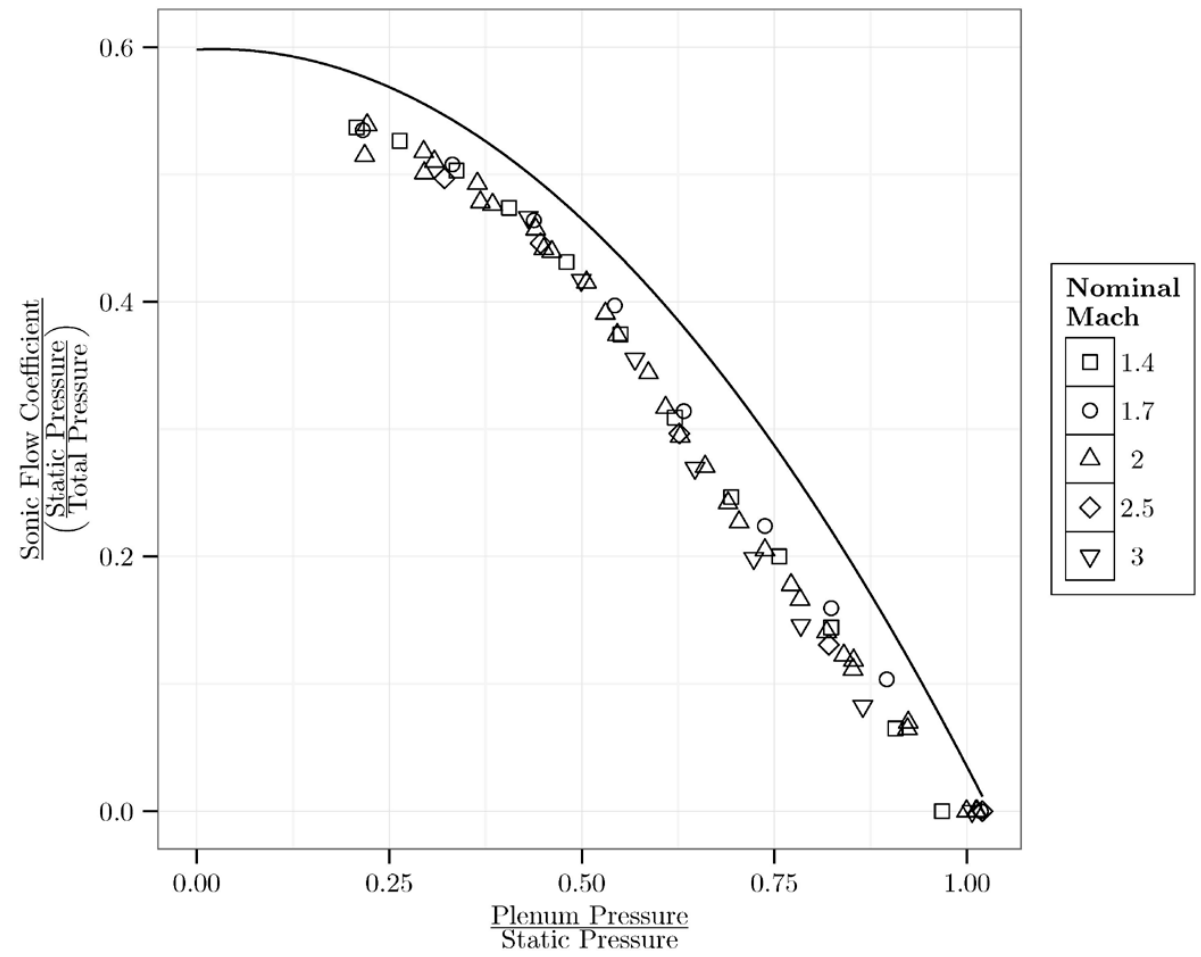

Figure 9.-Comparison of the Slater correlation to bleed configuration 102.

Three different statistical models were calculated, all were based upon a cubic in scaled plenum pressure and linear interactions in the other independent variables. The first model was a full interaction with 64 coefficients. This model was cumbersome, but has a multiple r-squared error of 99.11 percent. A reduced term model considering only first order interactions had 26 coefficients and a multiple r-squared error of 98.80 percent. Graphically, it was observed that this model deviated somewhat from the data and the full interaction model. An intermediate model was then considered using selected interactions where it was possible to develop a model with 43 coefficients that has a multiple r-squared error of 99.05 percent and that exhibited a negligible difference graphically from the full interaction model. The residual standard error for this model is 0.02185 on 972 degrees of freedom. The equation for the model is given as:

$$
Q_{\text {scaled }}=\sum_{i=1}^{43} c_{i} \cdot I_{i}
$$

where $c_{i}$ are the interaction coefficients and $I_{i}$ are the interaction terms which are both summarized in Table 3. The resulting statistical fit is compared to selected data in Figure 10. Both the 26 term fit and the 43 term fit are compared illustrating a reasonable fit for the 43 term model of Table 3 . This fit is considered preliminary only as refinements will be made as further data is collected and analyzed.

\section{Computational Fluid Dynamics}

CFD was run using the method described by Slater (Ref. 4). The simulations were run at Mach 1.58 with a hole diameter of $6.35 \mathrm{~mm}$ The center cross-section Mach number plots are shown in Figure 11. In the results, it is readily seen that there are two distinct flow regimes with a change over between $60^{\circ}$ and $45^{\circ}$. As the $55^{\circ}$ holes showed a response similar to the $90^{\circ}$ holes we can conclude that the flow transition of the hole and a bow shock from the downstream edge of the hole whereas the $20^{\circ}$ hole experiences neither of these. The increase in scaled sonic flow coefficient between the $55^{\circ}$ and the $90^{\circ}$ holes is apparent in that the $55^{\circ}$ hole exhibits less separation and has a smaller wedge angle at the downstream 
edge of the hole. Both of these properties cause the intersection of the shear-layer and the bow shock to occur deeper in the hole such that the effective minimum flow area is increased.

TABLE 3.-BLEED MODEL COEFFICIENTS AND INTERACTIONS

\begin{tabular}{|c|c|c|c|}
\hline Constant & Interaction & Estimate & Standard error \\
\hline$c_{1}$ & intercept & $5.923 \times 10^{-1}$ & $3.312 \times 10^{-2}$ \\
\hline$c_{2}$ & $P_{\text {plen }_{\text {scaled }}}$ & $-9.614 \times 10$ & $6.346 \times 10^{-1}$ \\
\hline$c_{3}$ & $P_{\text {plen }_{\text {saled }}}{ }^{2}$ & $-7.564 \times 10^{-2}$ & $6.700 \times 10^{-1}$ \\
\hline$c_{4}$ & $P_{\text {plen }_{\text {saled }}}{ }^{3}$ & $3.200 \times 10^{-1}$ & $6.772 \times 10^{-1}$ \\
\hline$c_{5}$ & $M$ & $8.268 \times 10^{-2}$ & $1.287 \times 10^{-2}$ \\
\hline$c_{6}$ & $\frac{D}{\delta_{1}}$ & $-3.081 \times 10^{-2}$ & $1.689 \times 10^{-2}$ \\
\hline$c_{7}$ & $\alpha$ & $-4.236 \times 10^{-3}$ & $5.582 \times 10^{-4}$ \\
\hline$c_{8}$ & $\frac{t}{D}$ & $1.450 \times 10^{-2}$ & $8.864 \times 10^{-3}$ \\
\hline$c_{9}$ & $P_{\text {plen }_{\text {scaled }}} M$ & $-7.148 \times 10^{-1}$ & $2.842 \times 10^{-1}$ \\
\hline$c_{10}$ & $P_{\text {plen }_{\text {saled }}}{ }^{2} M$ & $-1.247 \times 10^{-1}$ & $2.943 \times 10^{-1}$ \\
\hline$c_{11}$ & $P_{\text {plen }_{\text {saled }}}{ }^{3} M$ & $1.287 \times 10^{-1}$ & $2.614 \times 10^{-1}$ \\
\hline$c_{12}$ & $P_{\text {plen }_{\text {saled }}} \frac{D}{\delta_{1}}$ & $3.844 \times 10^{-1}$ & $1.661 \times 10^{-1}$ \\
\hline$c_{13}$ & $P_{\text {plen }_{\text {saled }}}{ }^{2} \frac{D}{\delta_{1}}$ & $5.820 \times 10^{-1}$ & $1.734 \times 10^{-1}$ \\
\hline$c_{14}$ & $P_{\text {plen }_{\text {saled }}}{ }^{3} \frac{D}{\delta_{1}}$ & $-1.547 \times 10^{-1}$ & $1.810 \times 10^{-1}$ \\
\hline$c_{15}$ & $P_{\text {plen }_{\text {scaled }}} \alpha$ & $4.210 \times 10^{-2}$ & $6.636 \times 10^{-3}$ \\
\hline$c_{16}$ & $P_{p^{\prime l e n} \text { scaled }}{ }^{2} \alpha$ & $-2.749 \times 10^{-2}$ & $6.911 \times 10^{-3}$ \\
\hline$c_{17}$ & $P_{p^{\prime l e n} n_{\text {scaled }}}^{3} \alpha$ & $-1.597 \times 10^{-4}$ & $6.691 \times 10^{-3}$ \\
\hline$c_{18}$ & $P_{\text {plen }_{\text {saled }}} \frac{t}{D}$ & $-7.733 \times 10^{-1}$ & $2.644 \times 10^{-1}$ \\
\hline$c_{19}$ & $P_{\text {plen }_{\text {scaled }}}{ }^{2} \frac{t}{D}$ & $-1.297 \times 10^{1}$ & $2.780 \times 10^{-1}$ \\
\hline$c_{20}$ & $P_{\text {plen }_{\text {scaled }}}{ }^{3} \frac{t}{D}$ & $-4.820 \times 10$ & $2.871 \times 10^{-1}$ \\
\hline$c_{21}$ & $M \frac{D}{\delta_{1}}$ & $-4.318 \times 10^{-2}$ & $9.045 \times 10^{-3}$ \\
\hline$c_{22}$ & $M \alpha$ & $-6.910 \times 10^{-4}$ & $2.049 \times 10^{-4}$ \\
\hline$c_{23}$ & $\frac{D}{\delta_{1}} \alpha$ & $7.601 \times 10^{-4}$ & $2.575 \times 10^{-4}$ \\
\hline$c_{24}$ & $\alpha \frac{t}{D}$ & $1.414 \times 10^{-3}$ & $2.141 \times 10^{-4}$ \\
\hline$c_{25}$ & $P_{\text {plen }_{\text {saladed }}} M \frac{D}{\delta_{1}}$ & $-6.286 \times 10^{-3}$ & $7.408 \times 10^{-2}$ \\
\hline$c_{26}$ & $P_{p \operatorname{len}_{\text {salled }}}{ }^{2} M \frac{D}{\delta_{1}}$ & $-2.389 \times 10^{-1}$ & $7.604 \times 10^{-2}$ \\
\hline$c_{27}$ & $P_{\text {plen }_{\text {saled }}}{ }^{3} M \frac{D}{\delta_{1}}$ & $3.678 \times 10^{-2}$ & $7.274 \times 10^{-2}$ \\
\hline$c_{28}$ & $P_{\text {plen }_{\text {scaled }}} M \alpha$ & $7.051 \times 10^{-3}$ & $3.218 \times 10^{-3}$ \\
\hline$c_{29}$ & $P_{p^{\prime l e n} n_{\text {saled }}}{ }^{2} M \alpha$ & $1.375 \times 10^{-2}$ & $3.290 \times 10^{-3}$ \\
\hline$c_{30}$ & $P_{\text {plen } n_{\text {scaled }}{ }^{3} M \alpha}$ & $-1.788 \times 10^{-3}$ & $2.814 \times 10^{-3}$ \\
\hline$c_{31}$ & $M \frac{D}{\delta_{1}} \alpha$ & $2.916 \times 10^{-4}$ & $1.125 \times 10^{-4}$ \\
\hline$c_{32}$ & $P_{\text {plen }_{\text {saled }}} M \frac{t}{D}$ & $3.903 \times 10^{-1}$ & $8.763 \times 10^{-2}$ \\
\hline$c_{33}$ & $P_{\text {plen }_{\text {scaled }}}{ }^{2} M \frac{t}{D}$ & $-3.032 \times 10^{-1}$ & $9.226 \times 10^{-2}$ \\
\hline$c_{34}$ & $P_{\text {plen }_{\text {saled }}}{ }^{3} M \frac{t}{D}$ & $3.082 \times 10^{-1}$ & $8.363 \times 10^{-2}$ \\
\hline$c_{35}$ & $P_{\text {plen }_{\text {scaled }}} \frac{D}{\delta_{1}}$ & $-8.032 \times 10^{-2}$ & $5.161 \times 10^{-2}$ \\
\hline$c_{36}$ & $P_{\text {plen }_{\text {scaled }}}{ }^{2} \frac{D}{\delta_{1}}$ & $9.751 \times 10^{-2}$ & $5.400 \times 10^{-2}$ \\
\hline$c_{37}$ & $P_{\text {plen }_{\text {scaled }}}{ }^{3} \frac{D}{\delta_{1}}$ & $2.486 \times 10^{-1}$ & $5.755 \times 10^{-2}$ \\
\hline
\end{tabular}


TABLE 3.-BLEED MODEL COEFFICIENTS AND INTERACTIONS

\begin{tabular}{|c|c|c|c|}
\hline Constant & Interaction & Estimate & Standard error \\
\hline$c_{38}$ & $M \frac{D}{\delta_{1}} \frac{t}{D}$ & $1.966 \times 10^{-2}$ & $2.419 \times 10^{-3}$ \\
\hline$c_{39}$ & $P_{\text {plen }_{\text {saled }}} \alpha \frac{t}{D}$ & $9.928 \times 10^{-4}$ & $1.930 \times 10^{-3}$ \\
\hline$c_{40}$ & $P_{\text {plen }_{\text {saled }}} \alpha \frac{t}{D}$ & $1.164 \times 10^{-2}$ & $2.004 \times 10^{-3}$ \\
\hline$c_{41}$ & $P_{\text {plen saled }_{\text {sale }}}{ }^{3} \alpha \frac{t}{D}$ & $-3.836 \times 10^{-3}$ & $2.053 \times 10^{-3}$ \\
\hline$c_{42}$ & $M \alpha \frac{t}{D}$ & $-4.764 \times 10^{-4}$ & $5.406 \times 10^{-5}$ \\
\hline$c_{43}$ & $\frac{D}{\delta_{1}} \alpha \frac{t}{D}$ & $-5.602 \times 10^{-4}$ & $6.232 \times 10^{-5}$ \\
\hline
\end{tabular}
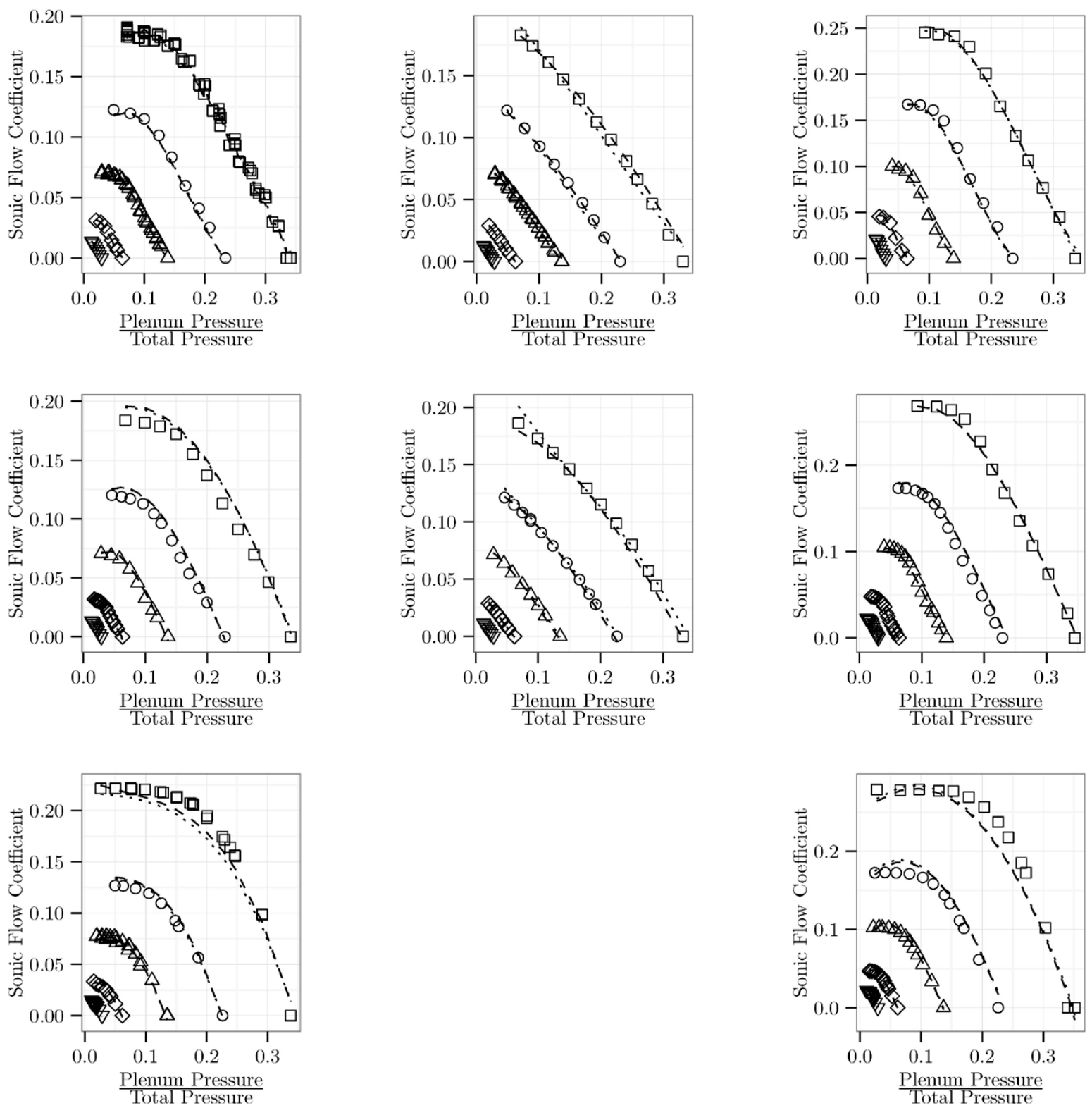

Figure 10.-Flow coefficient curves of selected plates compared to the statistical fit. Nominal Mach numbers: $\square-1.4$, $\bigcirc-1.7, \triangle-2.0, \diamond-2.5, \nabla-3.0$. 

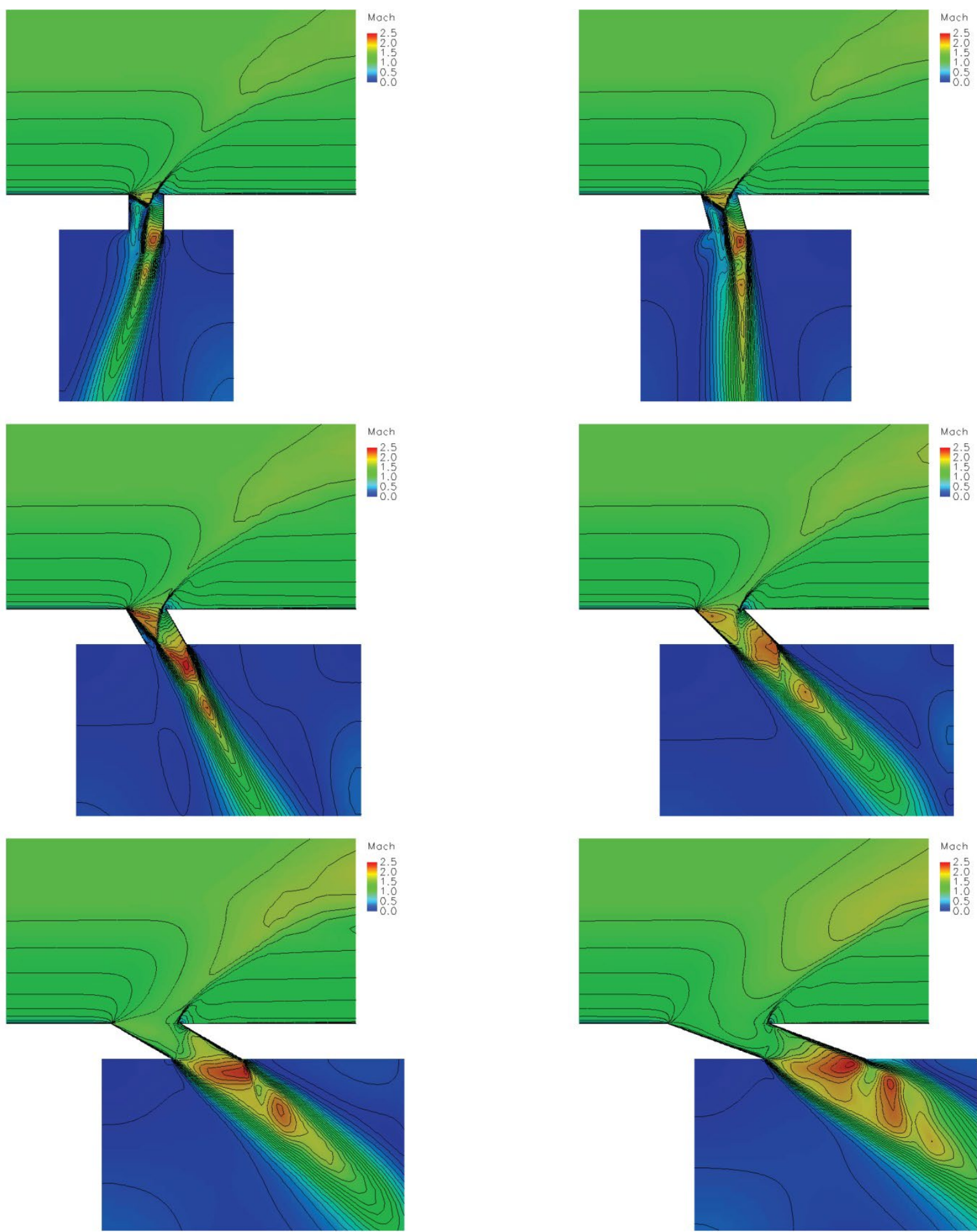

Figure 11.-CFD of a single round-hole at various hole inclination angles $(M=1.58)$.

\section{Summary and Conclusions}

Flow coefficient data for 21 bleed hole configurations at five Mach number conditions have been presented. This data is intended to be used for the development of flow coefficient models to be used by inlet designers and in CFD computer codes. The results show that for accurate bleed flow modeling of 
round holes, in addition to the local flow conditions, the effect of hole inclination angle, hole diameter, and bleed plate thickness must be included. While a physics based model is always desired and indeed have been attempted (Refs. 8, 9, and 10) the large number of parameters suggests that a statistical model, perhaps coupled with a simple flow model might be the best approach for a comprehensive flow coefficient model. And although they are likely secondary effects, a single-hole model might need to be extended to include hole array parameters such as hole-to-hole spacing and porosity.

\section{References}

1. McLafferty, G., and Ranard, E., "Pressure Losses and Flow Coefficients of Slanted Perforations Discharging from Within a Simulated Supersonic Inlet,” R-0920-1, United Aircraft Corp., East Hartford, Conn., 1958.

2. Willis, B.P., Davis, D.O., and Hingst, W.R., "Flow Coefficient Behavior for Boundary-Layer Bleed Holes and Slots," AIAA Paper 95-0031, 33rd AIAA Aerospace Sciences Meeting and Exhibit, Reno, NV, January 9-12, 1995 (also NASA TM-106846).

3. Davis, D.O., Grimes, M., and Schoenenberger, M., "Effect of Flow Misalignment and Multi-Hole Interaction on Boundary-Layer Bleed Hole Flow Coefficient Behavior," Proceedings of the ASME Fluids Engineering Division, FED-Vol. 242, American Soc. of Mech. Eng., New York, 1996, pp. 323-328 (also NASA TM-107480).

4. Slater, J. W., "Improvements in Modeling $90^{\circ}$ Bleed Holes for Supersonic Inlets," AIAA Paper 2009-0710, 47th AIAA Aerospace Sciences Meeting and Exhibit, Orlando, FL, January 5-8, 2009 (also NASA/TM-2009-215597).

5. Davis, D.O., "Fundamental Bleed Experiments at NASA Glenn Research Center 1995-1999," 1st Shock Wave/Boundary Layer Interaction Workshop, Cleveland, OH, April 15-16, 2008.

6. Davis, D.O., Vyas, M., and Slater, J., "Research on Supersonic Inlet Bleed," AIAA Paper 20120272, 50th AIAA Aerospace Sciences Meeting and Exhibit, Nashville, TN, January 9-12, 2012.

7. Davis, D.O., and Reichert, B.A., "Ethylene Trace-Gas Techniques for High-Speed Flows," AIAA Paper 94-0733, 32nd AIAA Aerospace Sciences Meeting and Exhibit, Reno, NV, January 10-13, 1994.

8. Harloff, G.J., and Smith, G.E., "On Supersonic-Inlet Boundary-Layer Bleed Flow,” AIAA Paper 950038, 33rd AIAA Aerospace Sciences Meeting and Exhibit, Reno, NV, January 9-12, 1995(also NASA CR-195426).

9. Manavasi, S., Morell, A., and Haned, A., "Investigation of Segmented Bleed Modeling in Supersonic Turbulent Boundary Layer," AIAA Paper 2011-0307, 49th AIAA Aerospace Sciences Meeting and Exhibit, Orlando, FL, January 4-7, 2011.

10. Bunnag, S., "Bleed Rate Model Based on Prandtl-Meyer Expansion for a Bleed Hole Normal to a Supersonic Stream," M.S. Thesis, Dept. of Aerospace Engineering and Engineering Mechanics, University of Cincinnati, Cincinnati, OH, May 2010. 


\begin{tabular}{|c|c|c|c|c|c|}
\hline \multicolumn{5}{|c|}{ REPORT DOCUMENTATION PAGE } & $\begin{array}{l}\text { Form Approved } \\
\text { OMB No. 0704-0188 }\end{array}$ \\
\hline \multicolumn{6}{|c|}{$\begin{array}{l}\text { The public reporting burden for this collection of information is estimated to average } 1 \text { hour per response, including the time for reviewing instructions, searching existing data sources, gathering and maintaining the } \\
\text { data needed, and completing and reviewing the collection of information. Send comments regarding this burden estimate or any other aspect of this collection of information, including suggestions for reducing this } \\
\text { burden, to Department of Defense, Washington Headquarters Services, Directorate for Information Operations and Reports (0704-0188), } 1215 \text { Jefferson Davis Highway, Suite } 1224 \text {, Allington, VA } 222202-402 \text {. } \\
\text { Respondents should be aware that notwithstanding any other provision of law, no person shall be subject to any penalty for failing to comply with a collection of information if it does not display a currently valid OMB } \\
\text { control number. } \\
\text { PLEASE DO NOT RETURN YOUR FORM TO THE ABOVE ADDRESS. }\end{array}$} \\
\hline \multicolumn{2}{|c|}{$\begin{array}{l}\text { 1. REPORT DATE (DD-MM-YYYY) } \\
01-02-2013\end{array}$} & \multicolumn{3}{|c|}{$\begin{array}{l}\text { 2. REPORT TYPE } \\
\text { Technical Memorandum }\end{array}$} & 3. DATES COVERED (From - To) \\
\hline \multirow{3}{*}{\multicolumn{5}{|c|}{$\begin{array}{l}\text { 4. TITLE AND SUBTITLE } \\
\text { Effect of Boundary-Layer Bleed Hole Inclination Angle and Scaling on Flow Coefficient } \\
\text { Behavior }\end{array}$}} & 5a. CONTRACT NUMBER \\
\hline & & & & & 5b. GRANT NUMBER \\
\hline & & & & & 5c. PROGRAM ELEMENT NUMBER \\
\hline \multirow{3}{*}{\multicolumn{5}{|c|}{$\begin{array}{l}\text { 6. AUTHOR(S) } \\
\text { Eichorn, Michael, B.; Barnhart, Paul, J.; Davis, David, O.; Vyas, Manan, A.; Slater, John, V }\end{array}$}} & 5d. PROJECT NUMBER \\
\hline & & & & & 5e. TASK NUMBER \\
\hline & & & & & $\begin{array}{l}\text { 5f. WORK UNIT NUMBER } \\
\text { WBS 984754.02.07.03.13.02 }\end{array}$ \\
\hline \multicolumn{5}{|c|}{$\begin{array}{l}\text { 7. PERFORMING ORGANIZATION NAME(S) AND ADDRESS(ES) } \\
\text { National Aeronautics and Space Administration } \\
\text { John H. Glenn Research Center at Lewis Field } \\
\text { Cleveland, Ohio 44135-3191 }\end{array}$} & $\begin{array}{l}\text { 8. PERFORMING ORGANIZATION } \\
\text { REPORT NUMBER } \\
\text { E-18617 }\end{array}$ \\
\hline \multirow{2}{*}{\multicolumn{5}{|c|}{$\begin{array}{l}\text { 9. SPONSORING/MONITORING AGENCY NAME(S) AND ADDRESS(ES) } \\
\text { National Aeronautics and Space Administration } \\
\text { Washington, DC 20546-0001 }\end{array}$}} & $\begin{array}{l}\text { 10. SPONSORING/MONITOR'S } \\
\text { ACRONYM(S) } \\
\text { NASA }\end{array}$ \\
\hline & & & & & $\begin{array}{l}\text { 11. SPONSORING/MONITORING } \\
\text { REPORT NUMBER } \\
\text { NASA/TM-2013-217843 }\end{array}$ \\
\hline \multicolumn{6}{|c|}{$\begin{array}{l}\text { 12. DISTRIBUTION/AVAILABILITY STATEMENT } \\
\text { Unclassified-Unlimited } \\
\text { Subject Category: } 02 \\
\text { Available electronically at http://www.sti.nasa.gov } \\
\text { This publication is available from the NASA Center for AeroSpace Information, 443-757-5802 }\end{array}$} \\
\hline \multicolumn{6}{|c|}{ 13. SUPPLEMENTARY NOTES } \\
\hline \multicolumn{6}{|c|}{$\begin{array}{l}\text { 14. ABSTRACT } \\
\text { Phase II data results of the Fundamental Inlet Bleed Experiments study at NASA Glenn Research Center are presented which include flow } \\
\text { coefficient behavior for } 21 \text { bleed hole configurations. The bleed configurations are all round holes with hole diameters ranging from } 0.795 \\
\text { to } 6.35 \mathrm{~mm} \text {, hole inclination angles from } 20^{\circ} \text { to } 90^{\circ} \text {, and thickness-to-diameter ratios from } 0.25 \text { to } 2.0 \text {. All configurations were tested at a } \\
\text { unit Reynolds number of } 2.46 \times 10^{7} / \mathrm{m} \text { and at discrete local Mach numbers of } 1.33,1.62,1.98,2.46 \text {, and } 2.92 \text {. Interactions between the design } \\
\text { parameters of hole diameter, hole inclination angle, and thickness-to-diameter as well as the interactions between the flow parameters of } \\
\text { pressure ratio and Mach number upon the flow coefficient are examined, and a preliminary statistical model is proposed. An existing } \\
\text { correlation is also examined with respect to this data. }\end{array}$} \\
\hline \multicolumn{6}{|c|}{$\begin{array}{l}\text { 15. SUBJECT TERMS } \\
\text { Flow coefficients; Inlet flow; Mach number; Static pressure; Supersonic flow; Supersonic inlets; Bleeding; Boundary layer control; } \\
\text { Boundary layer flow; Boundary layer separation; Compressible flow }\end{array}$} \\
\hline \multicolumn{3}{|c|}{ 16. SECURITY CLASSIFICATION OF: } & $\begin{array}{l}\text { 17. LIMITATION OF } \\
\text { ABSTRACT }\end{array}$ & $\begin{array}{l}\text { 18. NUMBER } \\
\text { OF }\end{array}$ & $\begin{array}{l}\text { 19a. NAME OF RESPONSIBLE PERSON } \\
\text { STI Help Desk (email:help@sti.nasa.gov) }\end{array}$ \\
\hline $\begin{array}{l}\text { a. REPORT } \\
\text { U }\end{array}$ & $\begin{array}{l}\text { b. ABSTRACT } \\
\text { U }\end{array}$ & $\begin{array}{l}\text { c. THIS } \\
\text { PAGE } \\
\text { U }\end{array}$ & UU & $\begin{array}{l}\text { PAGES } \\
24\end{array}$ & $\begin{array}{l}\text { 19b. TELEPHONE NUMBER (include area code) } \\
443-757-5802\end{array}$ \\
\hline
\end{tabular}



